\title{
COMPETITIVE RESPONSE HIERARCHIES FOR GERMINATION, GROWTH, AND SURVIVAL AND THEIR INFLUENCE ON ABUNDANCE
}

\author{
Timothy G. Howard ${ }^{1}$ And Deborah E. Goldberg
}

Department of Biology, University of Michigan, Ann Arbor, Michigan 48109-1048 USA

\begin{abstract}
Among plants, differences in competition intensity and in the ranking of competitive ability for traits such as germination, growth, and survival may suggest that the importance of competition for population success varies with the trait measured. If a species is a good competitor when measured by one component of fitness (e.g., seedling growth), but a poor competitor when measured by a different component of fitness (e.g., seedling survival), understanding the relative importance of each component of fitness for persistence in the community is critical to understanding how communities are structured. Using a field and a garden experiment in southeastern Michigan, we generated competitive response hierarchies among 4-8 old-field perennials for five components of fitness (germination, seedling growth, seedling survival, adult growth, and adult survival). We examined how the overall response to neighbors changes among components of fitness, the concordance of hierarchies within and among components of fitness, and the correlations between competitive hierarchies and natural abundance. We found little to no overall effect of neighbors on germination and seedling survival, indicating a high tolerance $(=$ strong response competitive ability) of species for neighbors as measured by these components of fitness. We found a strong effect of neighbors on seedling growth, and on adult survival and growth, indicating poorer response competitive ability overall for these components. Although rankings of competitive ability were concordant among species across all components of fitness, certain demographic parameters were more consistent in their rankings than others. Specifically, competitive response hierarchies based on size were strongly concordant, while those based on survival were not. This suggests that future studies may effectively estimate response competitive ability for growth with a single estimate, but that estimates of response competitive ability for survival at both the seedling and adult stages may be required. Finally, competitive response rankings based on germination and seedling growth were most strongly correlated with abundance, suggesting that these components of fitness more strongly influence success in the community than do seedling survival and adult growth and survival.
\end{abstract}

Key words: adult; competitive hierarchy; competitive response; components of fitness; field experiments; germination; growth; natural abundance; old-field community; seedling; survival.

\section{INTRODUCTION}

Ecologists appear in general agreement that competition has the potential to influence local plant species abundance, as reflected by the many models of the influence of competition on plant community structure (e.g., Grime 1977, Tilman 1982, 1990, Warner and Chesson 1985, Keddy 1990). However, because of the complexity of agestructured or size-structured models, formal theory rarely explicitly allows for stage-specific values of either the occurrence and magnitude of competition, or of the ranking of competitive ability among species. Similarly, in experimental studies, estimates of competitive ability in plants are most often based on a single response variable at a single life stage (e.g., Austin et al.1988, Canham 1988, Keddy et al. 1994, Wilson 1994). If competitive ability changes over the life history of a plant, such studies

Manuscript received 19 January 1999; revised 14 March 2000; accepted 15 March 2000.

${ }^{1}$ Present address: New York Natural Heritage Program, 700 Troy-Schenectady Road, Latham, New York 12110 USA. E-mail: tghoward@gw.dec.state.ny.us may not be relevant to the population-level outcome of interspecific competition. Thus, to understand the influence of competition on population dynamics and community structure (or the ultimate outcome of competition; sensu Welden and Slauson 1986), it is critical to determine how multiple response variables, such as growth, germination, and survival, at multiple life history stages, are influenced by competition.

While it is clear that the magnitude and even the direction (competition or facilitation) of interactions can change over the life history of a single species (e.g., Gurevitch 1986, De Steven 1991a, b), it is less well known how competitive hierarchies among multiple species change over life histories, and the ecological consequences of such changes if they were to occur. Are some species superior competitors as seedlings, and others superior as adults? Are some species superior competitors in terms of growth, and others in terms of survival? Although abundant data are available to evaluate plant performance at multiple life stages, most demographic studies focus on a single species; 
rarely is the purpose to compare competitive abilities among species (but see Grace 1985, Gerry and Wilson 1995). Indeed, competition among species has also been considered to occur directly only through growth, with other factors influencing fecundity, emergence, and survival (Grubb et al. 1982).

The ecological consequences of changing competitive hierarchies over life histories depend on the magnitude of influence of each life history stage on individual and population growth. If competition is an important process influencing relative abundance of species in a community, the magnitude of influence of each life history stage can be indirectly assessed by correlating rank in competitive ability at each life history stage with rank in natural abundance. In general, previous studies tend to show a positive relationship between competitive ability and abundance (e.g., Mitchley and Grubb 1986, Miller and Werner 1987, Aplet and Laven 1993). However, some studies have found that the correlation between competitive ability and abundance depends on which response variable is measured (Gurevitch 1986, De Steven 1991a, b). While some life history stages may influence final abundance more than others, these differences in importance may be independent of the intensity of competition (Welden and Slauson 1986). To further understand the influence of competition on community structure, we need to compare the intensity of competition and the degree of consistency of competitive abilities across different measures of competitive response. This will enable us to determine how closely rankings of competitive ability for each of these distinct responses are correlated with rankings in natural abundance. These are the goals of this paper.

We addressed the following questions: (1) How does the magnitude of competition (i.e., overall response to neighbors) differ among components of fitness? (2) How concordant are hierarchies of competitive ability among components of fitness? (3) For which components of fitness are competitive hierarchies most correlated with hierarchies of natural abundance? By "components of fitness," we refer to the multiple combinations of different demographic parameters (germination, survival, and growth) at different life history stages (seedlings and adults), that each contribute to net individual fitness and per capita population growth. In this study, we focus only on comparisons of response competitive ability among these components of fitness, i.e., the relative ability of individuals of different species to tolerate or avoid suppression by neighbors (sensu Goldberg and Werner 1983). Effect competitive ability, i.e., the relative ability of individuals to suppress other individuals, is discussed elsewhere (Howard 2001).

\section{Methods}

We measured response competitive ability of plants in two distinct ways and used a total of eight species in both experiments. First, we quantified the response of both seedling and adult targets to all naturally occurring neighbors in a field removal experiment. This method compares effects at natural community abundance, which is perhaps the most relevant density for ascertaining the magnitude of neighbor suppression under field conditions (Goldberg and Scheiner 1993). However, the disadvantage of this method is that perunit neighbor effects cannot be extrapolated to other densities unless linear effects with density are assumed. This is rarely the case (Watkinson 1980, Silander and Pacala 1985). Therefore, we also quantified the growth and survival response of seedling targets to a gradient in density of neighbors in a garden experiment. Pergram differences in target response were evaluated by comparing the shape of the curves of nonlinear regressions of target performance on neighbor biomass. Neighbors were planted along with the targets in the garden experiment and thus neighbor identity was controlled, whereas, in the field experiment, all species in the background community were used as a single taxon of neighbors.

\section{Removal experiment in the field}

The removal experiment was conducted in a 70-yrold field at the Edwin S. George Reserve in Pinckney, Michigan (UTM Zone 17: 4705000 m N, 251700 m E). The field is on sandy soil and is dominated by herbaceous perennial vegetation, although brambles (Rubus flagellaris Willd.) are also common. We chose seven common species to use as targets to encompass the variety of nonwoody life forms in the field: Achillea millefolium L., Centaurea maculosa Lam., Chrysanthemum leucanthemum L., Danthonia spicata (L.) F. Beauv., Hieracium piloselloides Villars., Poa compressa L., and Rumex acetosella L. (Table 1). Nomenclature follows Gleason and Cronquist (1991). We refer to each species by its generic name for the remainder of this paper.

Treatments and timing.-The two-year field removal experiment consisted of a two-way factorial, randomized block design for each life history stage (seedlings and adults). For seedling targets, there were three neighbor treatments (all adult and seedling neighbors present [AN], only seedling neighbors present [SN], and no neighbors present $[\mathrm{NN}]$ ), and seven target species, for a total of 21 treatment combinations. The design for adult targets was identical except that the SN treatment was dropped, for a total of 14 treatment combinations. Seedling and adult neighbors included all individuals of that life history stage naturally occurring in a plot, regardless of species.

We randomly applied the 35 treatments to round plots (radius $=28.2 \mathrm{~cm}$ with $0.64 \mathrm{~m}$ between plot edges) within five replicate blocks, in early May 1995. All NN and SN plots were treated with a general herbicide (Roundup, Monsanto Corporation, St. Louis, Missouri) on 13 May 1995, using a sponge applicator. All above- 
TABLE 1. Targets used in the field removal (F) and garden gradient $(\mathrm{G})$ experiments.

\begin{tabular}{|c|c|c|c|c|c|}
\hline Species & $\begin{array}{c}\text { Experi- } \\
\text { ment }\end{array}$ & Aboveground & Belowground & $\begin{array}{l}\text { Initial } \\
\text { mass }(\mathrm{g})\end{array}$ & $\begin{array}{l}\text { Maximum } \\
\text { mass }(\mathrm{g}) \\
\text { garden } \\
\text { experiment }\end{array}$ \\
\hline Poa & $\mathrm{F}, \mathrm{G}$ & grass & rhizomatous & 0.090 & 3.7 \\
\hline Centaurea & $\mathrm{F}, \mathrm{G}$ & rosette & not spreading & 0.130 & 100.0 \\
\hline Rumex & $\mathrm{F}, \mathrm{G}$ & spreading & rhizomatous & 0.099 & 56.8 \\
\hline Hieracium & $\mathrm{F}, \mathrm{G}$ & rosette & short rhizomes & 0.255 & 31.2 \\
\hline Danthonia & $\mathrm{F}$ & bunchgrass & short tillers & 1.437 & $\ldots$ \\
\hline Hypericum & $\mathrm{G}$ & upright & not spreading & $\ldots$ & 49.2 \\
\hline Chrysanthemum & $\mathrm{F}, \mathrm{G}$ & spreading & short rhizomes & 0.274 & 111.6 \\
\hline Achillea & $\mathrm{F}, \mathrm{G}$ & rosette & rhizomatous & 0.080 & 88.6 \\
\hline
\end{tabular}

Notes: The aboveground and belowground growth forms describe stature and spreading habits of each species. Additionally, Centaurea is a taprooted perennial, Hypericum is intermediate with both tap and fibrous roots; all other species are fibrous-rooted perennials. Initial shoot mass of adult transplants at the beginning of the field removal experiment was calculated using stepwise regression with additional plants measured and harvested at the beginning of the experiment (Howard 1998).

ground biomass was removed after $10 \mathrm{~d}$. Spot herbicide treatments were repeated on 12 June for late-emerging perennials. In the NN treatment, all re-emerging perennials and any germinating seedlings were removed during the experiment. In the SN treatment plots, all subsequent emerging seedlings were allowed to remain, while adults emerging from rootstocks or runners were removed by clipping at ground level. The AN treatment was left undisturbed, aside from the addition of targets in the center of the plots, until the termination of the experiment.

In each plot requiring seedling targets, we planted 100 seeds (50 for Danthonia; all seeds were collected on site) of the designated target species within a $5 \mathrm{~cm}$ diameter area in the center of the plot. If more than one seedling remained after monitoring germination and survival through an early establishment phase, we weeded the plot to a single target seedling. Seeds were planted between 29 May and 2 June. In each plot requiring adult targets, we transplanted a single adult ramet, collected as a cylindrical plug, $4 \mathrm{~cm}$ in diameter by $10 \mathrm{~cm}$ deep, from another area of the same field. To estimate the initial mass of the experimental plants, an additional 20 individuals of each species were collected, measured, and dried. Transplants were collected, measured, and planted between 19 and 21 May 1995.

Replanting, monitoring and harvest.-Adults that did not survive the initial transplanting were replaced 3-4 June 1995 (all Danthonia and seven of the 60 individuals of the other species). We watered each of the replanted individuals upon planting, and then watered all individuals periodically from 7-24 June, after which we left the experiment to natural rainfall conditions. Danthonia survival through the winter was extremely poor, so all adult Danthonia were again replanted on 10 June 1996. To reduce desiccation, each of those replanted individuals was shaded with a cardboard rectangle $(10 \times 12 \mathrm{~cm})$ staked in the ground to cast shade on the target during the hottest times of day.
Because of poor germination and low overwinter survival of seedlings, we repeated the target seedling portion of the experiment in the spring of 1996, in the same plots. This time, we began seedlings in an environmental chamber and grew them to the two-leaf stage (beyond cotyledons) before planting them in the field. We planted three of these seedlings per plot from 27 May to 3 June 1996. Each seedling was initially shaded to alleviate midday desiccation; after establishment, surviving seedlings were thinned to a single seedling per plot.

We harvested aboveground biomass of all living targets and their respective neighbors on 25 October 1996, after two complete growing seasons for adults and one for seedlings. All plants were dried at $60^{\circ} \mathrm{C}$ and weighed to the nearest $0.001 \mathrm{~g}$.

Analyses.-To test for the presence of competition and differences in competitive ability among species (the species $\times$ competition interaction), we conducted a series of two-way (species and competition) randomized complete block analyses of variance for seed germination, seedling survivorship, and adult mass. For seedling mass, high mortality precluded the complete two-way ANOVA, so we conducted two one-way ANOVAs instead, with either species or competition as independent variables. Adult survivorship was analyzed using a nominal logistic model with likelihoodratio effects tests. ANOVAs were conducted with JMP (SAS Institute, Cary, North Carolina, USA), which deals with missing cells (here, due to mortality) slightly differently than Type III hypothesis tests, but is equivalent to testing that the least squares means are different when estimable. If least squares means are nonestimable, then the test drops these comparisons and loses degrees of freedom (SAS Institute 1995). We further investigated nonsignificant effects with power analyses. One estimate of the power of a test is the least significant number (LSN) required to get a significant effect given the same standard error and raw effect size. LSN is presented as an intuitive interpretation of how 
strongly the data reject the hypothesis that our tested factors differ, not as a suggestion that an experiment with more replication would have changed the results.

To compare the rankings in competitive response among components of fitness, we compared the concordance of rankings of competitive ability. We used an index, the Relative Interaction Intensity (RII), to estimate the magnitude of competitive response for each species

$$
\mathrm{RII}=\frac{T_{+\mathrm{N}}-T_{-\mathrm{N}}}{\max \left|T_{-\mathrm{N}}\right| \text { or }\left|T_{+\mathrm{N}}\right|}
$$

where $T_{-\mathrm{N}}$ is the performance of the target in the absence of neighbors and $T_{+\mathrm{N}}$ is the performance of the target in the presence of neighbors (Suding and Goldberg 1999). RII is equivalent to another common index, RCI (Grace 1995), under competitive interactions. However, RII is symmetrical around zero and constrained by both +1 and -1 (Markham and Chanway 1996), so that magnitudes of competition and facilitation are comparable. We calculated RII by block for each treatment combination, and then tested for concordance of RII rankings among different groupings of components of fitness with Friedman two-way ANOVA using SYSTAT (SPSS, Chicago, Illinois, USA). A significant finding from a Friedman ANOVA allows us to reject the null hypothesis that ranks within components of fitness are randomly organized and accept the notion that rankings of competitive ability are similar for different components of fitness.

\section{Garden gradient experiment}

We estimated the per-gram competitive response of species for seedling survival and seedling mass in a separate garden experiment. Per-gram competitive responses may differ from the total competitive responses measured in the field removal experiment, so this experiment provides alternative, independent estimates of competitive response at the seedling stage. We established the garden gradient experiment in 1994 in a formerly forested site that had been cleared and leveled in 1988 , and was now occupied by a mixture of native and non-native prairie and old-field species (T. G. Howard, unpublished data). This site was $1280 \mathrm{~m}$ from the field experiment at the Edwin S. George Reserve in Pinckney, Michigan. With a rear-tine rototiller, we tilled an area $\sim 30 \times 21 \mathrm{~m}$ to a depth of $\sim 20 \mathrm{~cm}$, and erected a deer fence around the site to exclude large herbivores.

The experiment consisted of a pairwise matrix of seven target species and six neighbor species, with all possible target-neighbor combinations in the design. Achillea, Centaurea, Chrysanthemum, Hieracium, Hypericum perforatum L., Poa, and Rumex served as targets, and all species but Rumex served as neighbors (see Table 1 for growth form descriptions). For each target-neighbor combination, we used an additive design of eight densities arranged in a modified hexagonal fan array. Each target was planted in the middle of six neighbors. The neighbors encircled the target in the form of a hexagon. Eight connected hexagons with decreasing side lengths formed a fan of eight densities (see Antonovics and Fowler 1985 and Kunin 1993 for a discussion of hexagonal fan arrays and geometry). Eighteen of the 42 target-neighbor combinations were represented by two fans; the remainder were represented by a single fan. At the end of the experiment, we quantified both seedling survival and seedling growth by harvesting and weighing aboveground and belowground biomass of all surviving plants.

While each target-neighbor combination had eight densities, these densities were restricted to a single locality (the fan) for most combinations, and were not randomly dispersed throughout the block. Thus, comparisons at the individual species level for both targets and neighbors (a full design of target $\times$ neighbor effects and interactions) are autocorrelated and violate the assumption of independence. Instead, we combined all neighbors for each target species to get a mean response competitive ability that could be statistically compared among target species.

Planting and maintenance.-We planted seeds of Poa, Hypericum, Hieracium, Achillea, Chrysanthemum, Centaurea, and Rumex in sifted germinating medium in a greenhouse from 27 April to 2 May 1994. Based on information from previous trials, we varied the timing of sowing among species to equalize the timing of emergence. All seeds had been collected on site. All seedlings were transplanted to flats on 7-9 May 1994. Between 9 June and 19 June, we planted 2520 of these seedlings in 60 fans. The space between each planted individual in each fan, and between fans, was kept clear by clipping weed seedlings at the soil surface with a hoe.

Harvest and analysis.-After one growing season, between 23 September and 17 October 1994, we harvested the root and shoot biomass for all living targets in all fans. We harvested neighbor roots and shoots in 14 fans and only neighbor shoots in the remaining 46 fans. Roots were extracted by washing them from the soil. Shoots were harvested by clipping at ground level.

To assess how neighbor density influenced target survival, we used logistic regression to test for effects of neighbor density and target identity on the number of target individuals surviving to harvest. Distance to the nearest neighbor was used as a simple approximation of neighbor density. A significant interaction between target-species identity and neighbor density would indicate that target species respond differently to changes in neighbor density.

To investigate how neighbor density influenced target growth, we plotted the performance of each target against an index of neighbor standing crop for all neighbors. Target performance was represented by the total aboveground and belowground biomass of each individual, standardized for each species to the maxi- 
mum biomass attained in the experiment. The neighbor standing crop index was calculated as

$$
N=\sum_{i \rightarrow n} \frac{a_{i}}{D_{i}^{2}}
$$

where $a$ is aboveground neighbor biomass, $D$ is the distance of the neighbor to the target, and each $i$ represents each neighbor harvested in the hexagon surrounding the target. $N$ is directly related to standing crop, and follows neighborhood models of plant interference (Weiner 1982). The results were unchanged when we included neighbors outside the immediate hexagon in estimates of $N$.

We fit a nonlinear curve to the distribution of points in each plot of target biomass vs. neighbor standingcrop index using the standard reciprocal-yield relationship (Watkinson 1980, Weiner 1982)

$$
\frac{T}{T_{0}}=\frac{1}{1+c N}
$$

where $T$ is the target biomass, $T_{0}$ is the target biomass with no neighbors, and $c$ is a decay constant that describes the shape of the curve. To compare competitive abilities among species, we compared the values for $c$, and the overlap in their confidence intervals, calculated for each curve. A larger $c$ corresponds to a more sharply declining curve and thus the target exhibits less tolerance of neighbors and poorer response competitive ability.

\section{Correlating competitive hierarchies to hierarchies of abundance}

To estimate relative abundance of species in the field, we surveyed $1920.1-\mathrm{m}^{2}$ plots in 1996, in a sampling grid $30 \times 65 \mathrm{~m}$ in size (plots at 5-m intervals), in the undisturbed areas of the experimental field site. We identified all species present in each plot and estimated their percent cover by eye. We used the frequency of occurrence over all the plots as an estimate of natural abundance of each species; overall mean percent cover values were highly correlated with frequency and showed similar patterns (T. G. Howard, unpublished data).

To determine which types of competitive hierarchies were most correlated with the hierarchy of natural abundance, we used Spearman rank correlations $\left(r_{\mathrm{S}}\right)$ to compare the relationship between each competitive ranking and the 1996 ranking in natural abundance. Because we had 12 different competitive rankings, we used a random effects model resampling procedure to test the divergence of the distribution of $r_{\mathrm{S}}$ values from zero (using a $\mathrm{Z}$ transformation, weighted by sample size, resampled 4999 times using the computer program MetaWin 2.0; Rosenberg et al. 1999). A mean $r_{\mathrm{S}}$ significantly greater than zero based on bias-corrected 95\% confidence intervals indicates that better response competitors are more abundant.

\section{RESUlts}

\section{Field removal experiment}

At the end of the experiment, neighbor biomass differed significantly among all three neighbor treatments (mean $\pm 1 \mathrm{sE}, \mathrm{AN}: 159.2 \pm 5.2 \mathrm{~g} / \mathrm{m}^{2}$; SN: $53.2 \pm 10.4$ $\mathrm{g} / \mathrm{m}^{2} ; \mathrm{NN}: 8.4 \pm 4.8 \mathrm{~g} / \mathrm{m}^{2} ; P<0.0001, \mathrm{MS}=30.37$, $F=577.17)$ but did not differ among target species $(P=0.233$, MS $=0.074, F=1.43)$ or their interaction $(P=0.327, \mathrm{MS}=61.62, F=1.17)$, based on two-way ANOVA on log-transformed neighbor mass. Thus, neighbor biomass varied consistently in the direction manipulated.

Seedlings.- Seedling germination in year 1 and survival in both years differed among target species, but not among neighbor treatments or their interaction (Fig. 1; Table 2), indicating no competitive or facilitative effects overall, and no differences in response to neighbors among species. Power analyses of the nonsignificant components indicated that sample sizes of at least double to quadruple those used in the experiment would be needed to detect any further differences, and therefore, that the statistically nonsignificant results are also biologically nonsignificant (Howard 1998). Centaurea had the highest germination and the highest overall survival in both years, regardless of competitive regime, although this species was the only one experiencing significant competitive suppression of survival in both years (one-tailed $t$ test against a value of RII $=0.0$ in the AN treatment, adjusted for multiple comparisons using the Dunn-Šidák method; $P<0.06$ in year $1, P<0.001$ in year 2 ).

Too few seedlings survived in 1995 to analyze the influence of target identity or competition on seedling size; only 30 of 105 plots had any surviving seedlings, and about half of the seedlings were Centaurea. In 1996 , we were able to conduct two separate one-way ANOVAs, one to compare target species and one to assess competition. Despite the limited data, significant effects of competition on seedling biomass were detected overall (Table 2); seedlings were larger in the absence of neighbors in four of the five species in which any seedlings survived in this treatment (Fig. 1).

Adults.-The competition $\times$ species interaction was significant for survival of adult targets, suggesting that the magnitude of neighbor effects differed among target species, although neither of the main effects of competition or species were significant at $P<0.05$ (Table 2). Some species appeared to be inhibited by neighbors (Centaurea, Rumex, Danthonia), while others may have been facilitated (Poa, Hieracium) (Fig. 2).

In contrast to the weakly significant or nonsignificant results for adult survival, adult mass was strongly influenced by all the experimental factors: neighbor treatment, target species, and their interaction (Fig. 2; Table 2 ; in this analysis Danthonia growth represents only a single year; results are qualitatively identical if Dan- 

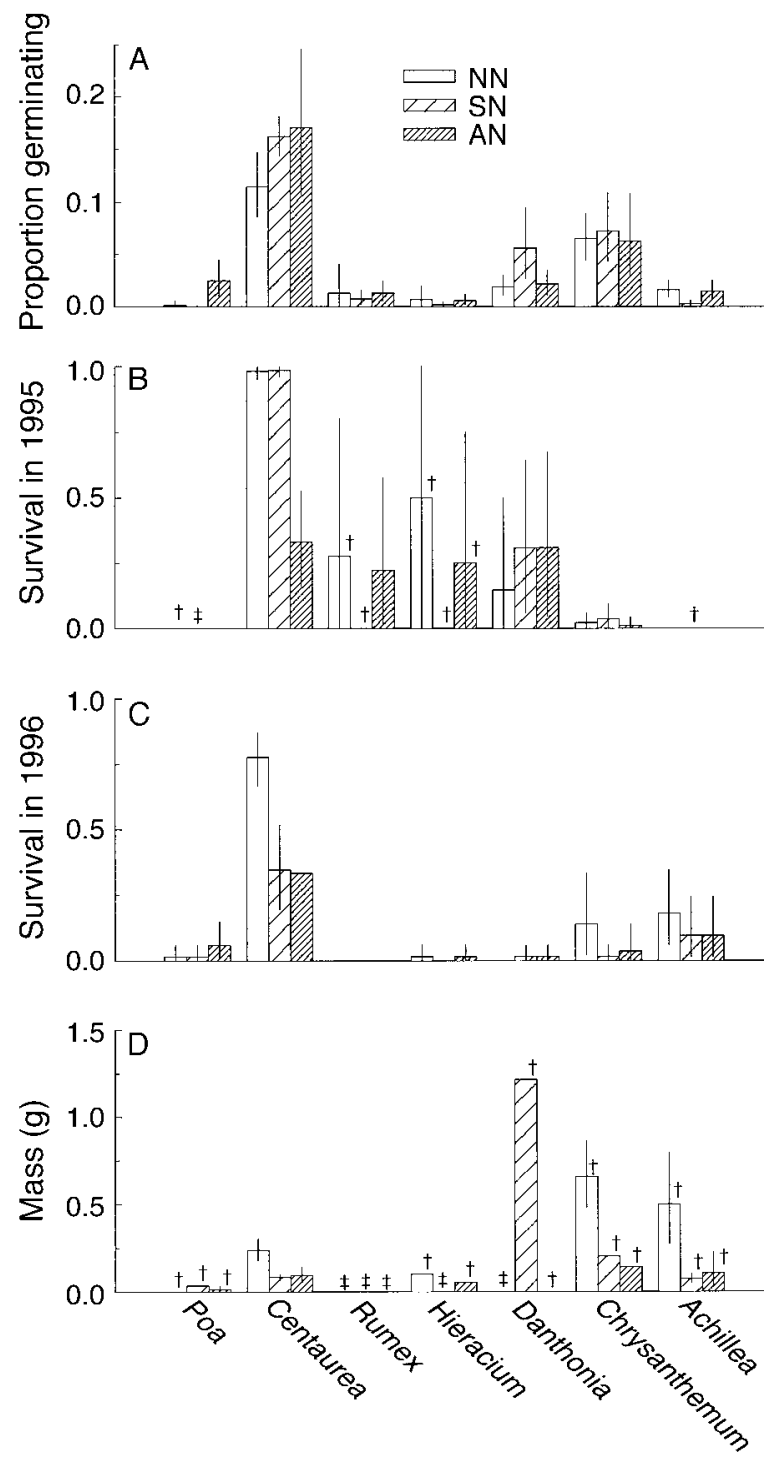

FIG. 1. Response of seedling targets for each treatmenttarget species combination in the field experiment. (A) Proportion of seeds germinating out of 100 seeds planted (50 for Danthonia). (B) Proportion of seedlings surviving to end of growing season out of those germinating in year one. (C) Proportion of seedlings surviving to end of growing season out of three planted per plot in year two. (D) Seedling mass $(\mathrm{g})$ at the end of 1996. Mean $\pm 1 \mathrm{SE}$ is shown for each trait and treatment-target species combination; data were backtransformed from transformations noted in Table 2. $N \geq 4$, except for $\dagger N<4$ and $\ddagger$ no data. ANOVA results are presented in Table 2.

thonia is removed from the analysis; Howard 1998). Targets were consistently larger ( $>9.5$-fold overall) in the absence of neighbors compared to the presence of adult and seedling neighbors, indicating strong competitive effects. Targets responded differently to the suppression of adult neighbors, with a range of $98 \%$ (Rumex; poor competitive response) to $21 \%$ (Danthon- ia; good competitive response) in reduction from $\mathrm{NN}$ to AN treatments (Fig. 2; Table 3).

Thus, for the field experiment overall, effects of competition on performance were weaker and less consistent than intrinsic differences among species. Species differed strongly in seed germination, seedling survival, and adult growth, and more weakly in seedling growth or adult survival. However, neighbors influenced only a subset of these components of fitness, with strongly significant main effects only on growth of both seedlings and adults. Only for adult survival and growth did species differ in response to neighbors, i.e., in competitive ability. However, for growth, all effects were strongly competitive, while for survival, effects ranged from positive to negative (Fig. 2).

\section{Garden gradient experiment}

Target species differed marginally in overall survival and in the extent to which survival was influenced by increasing neighbor density (logistic regression, species effect: $G=11.59,6 \mathrm{df}, P<0.1$; species $\times$ neighbor interaction: $G=11.63,6 \mathrm{df}, P<0.1)$. This interaction was largely due to the significant negative effect of neighbor distance on Chrysanthemum $(G=$ 8.61, $1 \mathrm{df}, P<0.01)$ and Achillea $(G=4.44,1 \mathrm{df}, P$ $<0.05$ ) and the lack of effect on the remaining species.

Six of the seven target species showed a significant and nonlinear reduction in size with increasing neighbor standing crop index, indicated by nonoverlap of 95\% confidence intervals around $c$ with zero (Fig. 3 ). The only exception was Rumex, which may be because of an avoidance response to competition. At high densities, some Rumex individuals sent runners through and resprouted outside the ring of neighbors.

Values for the competition index, $c$, varied among targets (Fig. 3). However, no species differed statistically in their per-gram competitive response, as indicated by the overlap in their $95 \%$ confidence intervals.

\section{Concordance of overall hierarchies (both experiments)}

Hierarchies of competitive response were compared among components of fitness using total competitive response (RII) for all response variables in the field removal experiment, and the per-gram response to neighbors ( $c$ and slope of logistic for growth and survival, respectively) for the garden gradient experiment (Table 3). For RII and the slope of logistic regressions, increasingly negative values indicate poorer response competitive ability, i.e., greater suppression in the presence of neighbors. For $c$, increasingly positive values indicate poorer response competitive ability. This difference in sign was corrected in all analyses. We included measures of competitive ability for all components of fitness in the comparisons, even though competition or differences in competitive ability among species were not always statistically detectable. Thus, we allowed for the possibility of a biological 
TABLE 2. Responses to competition in the field response experiment.

\begin{tabular}{|c|c|c|c|c|c|c|c|c|c|c|c|}
\hline \multirow[b]{3}{*}{ Response variables } & \multicolumn{9}{|c|}{ Effects } & & \\
\hline & \multicolumn{3}{|c|}{ Competition } & \multicolumn{3}{|c|}{ Species } & \multicolumn{3}{|c|}{ Competition $\times$ species } & \multicolumn{2}{|c|}{ Error } \\
\hline & $\mathrm{df}$ & MS & $F$ & df & MS & $F$ & $\mathrm{df}$ & MS & $F$ & $\mathrm{df}$ & MS \\
\hline \multicolumn{12}{|l|}{ Seedlings } \\
\hline Germination & 2 & 0.009 & 0.666 & 6 & 0.227 & $16.667 * * *$ & 12 & 0.011 & 0.781 & 84 & 0.014 \\
\hline Survival 1995 & 1 & 0.210 & 0.929 & 5 & 2.160 & $9.566 * * *$ & 11 & 0.298 & 1.321 & 52 & 0.225 \\
\hline Survival 1996 & 2 & 0.127 & 1.397 & 6 & 1.029 & $11.344 * * *$ & 12 & 0.069 & 0.757 & 84 & 0.091 \\
\hline Competition mass & 2 & 0.255 & $4.353 *$ & & & & & & & 30 & 0.059 \\
\hline Species mass $\$$ & & & & 5 & 0.129 & $2.159 \dagger$ & & & & 27 & 0.060 \\
\hline \multicolumn{12}{|l|}{ Adults } \\
\hline Survival§ & 1 & & $<0.001 \mathrm{~ns}$ & 6 & & $11.790 \dagger$ & 6 & & $13.752 *$ & 13 & 23.183 \\
\hline Final mass & 1 & 11.237 & $76.373 * * *$ & 6 & 0.508 & $3.452 * *$ & 6 & 0.804 & $5.463 * * *$ & 37 & 0.147 \\
\hline
\end{tabular}

Notes: Each row shows a separate ANOVA for the response variable indicated. Seedling survival is based on all of the germinating seeds in 1995, and the planted seedlings in 1996. Seedling and adult biomass is the aboveground mass of individuals harvested the fall of 1996. Proportion data (germination and seedling survival) were arcsine square-root transformed; size data were square-root transformed.

$* P<0.05, * * P<0.01, * * * P<0.001$.

$\dagger P<0.1$.

$\doteqdot$ High mortality precluded a two-way ANOVA for seedling mass; two one-way analyses were conducted instead.

$\S$ Tests for differences in adult survival use a nominal logistic model with likelihood-ratio effect tests on the proportion surviving to harvest. The likelihood-ratio chi square is supplied in the $F$-ratio column. The df noted in the error column is the degrees of freedom in the whole model test. The error column shows the df and chi square for the complete model.
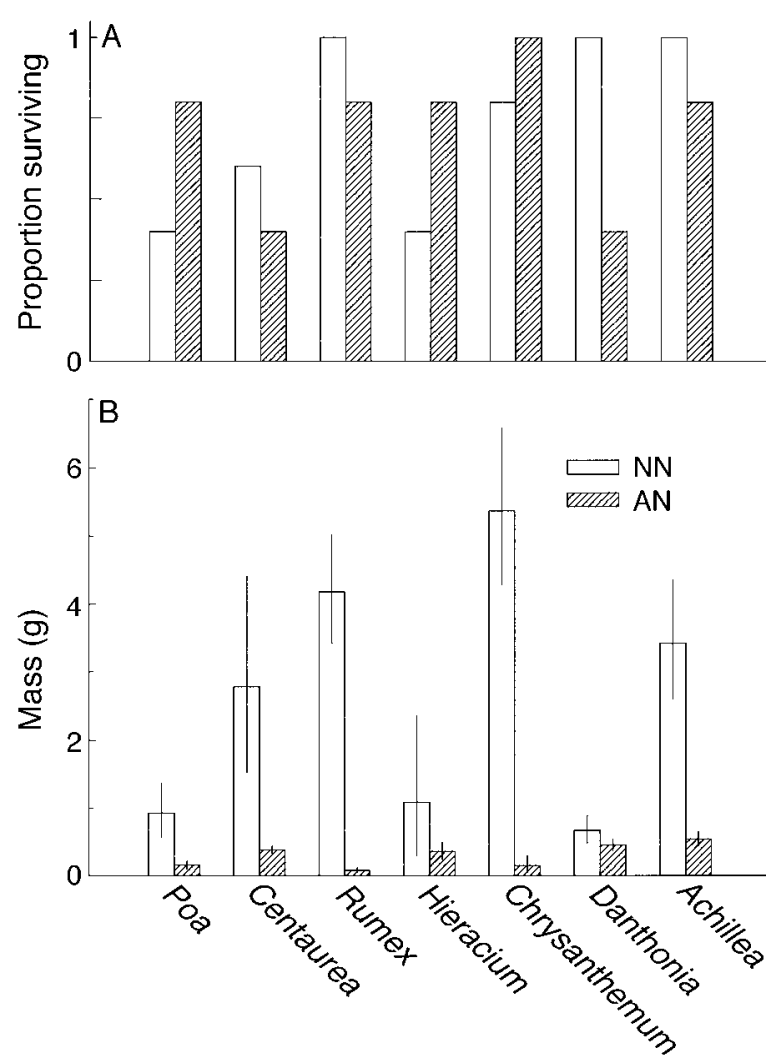

FIG. 2. Response of adult targets for each treatment-target species combination in the field removal experiment. (A) Proportion of targets surviving across all blocks (thus lacking variance). (B) Mass (g) at harvest with mean \pm 1 SE shown; data were backtransformed from square-root transformations. influence of competition even in the absence of statistically significant results.

Only four species (Achillea, Centaurea, Chrysanthemum, and Poa) had data on competitive response for 11 measured components of fitness (Table 3). Nevertheless, these were significantly concordant overall, indicating that these species have similar rankings of competitive abilities regardless of component of fitness measured (Table 4). On the other hand, although significant, the degree of concordance was relatively low (Kendall's $W=0.485$ ), indicating that the hierarchy for any one component of fitness would not be highly predictive of any other hierarchy. We then examined consistency of competitive ability within various subsets of the components of fitness measured and, with one major set of exceptions, found generally consistent hierarchies, although not always significant because of small sample sizes (i.e., few species with complete data within the subset or few hierarchies for comparison) (Table 4). The exceptions are that groups of hierarchies that compared only competitive ability in terms of survival, whether both seedling and adults or just seedlings, were completely unrelated $(W<0.10)$. Thus, larger groups of hierarchies that also involved more than one hierarchy in terms of survival, tended to be less concordant ( $W>0.40$ but $<0.50$ ) than hierarchies that involved only a single hierarchy in terms of survival ( $W>0.80$; "all adults" or "garden experiment"; Table 4). Groups of hierarchies comparing only growth (including both adults and seedlings), or only germination, were all highly concordant, i.e., had very similar rankings of competitive ability among species ( $W$ $>0.70$; Table 4).

\section{Relationships with natural abundance}

In general, species that were better response competitors tended to be more abundant. Not only were 
TABLE 3. Frequency of occurrence in the field site, competitive response ability for 11 components of fitness for eight oldfield perennial species, and Spearman rank correlations $\left(r_{\mathrm{S}}\right)$ between frequency and the different measures of competitive ability.

\begin{tabular}{|c|c|c|c|c|c|c|c|}
\hline \multirow[b]{4}{*}{ Species } & \multirow{4}{*}{$\begin{array}{c}\text { Fre- } \\
\text { quency }\end{array}$} & \multirow{3}{*}{\multicolumn{2}{|c|}{$\begin{array}{c}\text { Germination } \\
\text { Field } \\
\text { Seed }\end{array}$}} & \multicolumn{4}{|c|}{ Growth } \\
\hline & & & & \multicolumn{3}{|c|}{ Field } & \multirow{3}{*}{$\begin{array}{c}\text { Garden } \\
\text { Seedling } \\
\mathrm{S}\end{array}$} \\
\hline & & & & \multicolumn{2}{|c|}{ Seedling } & \multirow{2}{*}{$\frac{\text { Adult }}{\mathrm{A}}$} & \\
\hline & & A & $S$ & A & S & & \\
\hline$P o a$ & 0.94 & 0.80 & 0.20 & 0.89 & 0.94 & -0.71 & 15.48 \\
\hline Centaurea & 0.85 & 0.12 & 0.29 & -0.56 & -0.67 & -0.86 & 19.24 \\
\hline Rumex & 0.82 & 0.04 & -0.05 & $\ldots$ & $\ldots$ & -0.98 & $\ldots$ \\
\hline Hieracium & 0.64 & 0.07 & 0.00 & -0.47 & $\ldots$ & -0.54 & 19.26 \\
\hline Danthonia & 0.39 & -0.10 & 0.41 & $\ldots$ & $\ldots$ & -0.21 & $\ldots$ \\
\hline Hypericum & 0.31 & $\ldots$ & $\ldots$ & $\ldots$ & $\ldots$ & $\ldots$ & 25.91 \\
\hline Chrysanthemum & 0.28 & -0.03 & -0.05 & -0.79 & -0.70 & -0.95 & 21.90 \\
\hline Achillea & 0.12 & -0.18 & -0.50 & -0.77 & -0.87 & -0.81 & 23.05 \\
\hline$r_{\mathrm{S}}$ & & $90.93 * *$ & 0.52 & 0.80 & $91.00 * * *$ & -0.04 & 0.83 \\
\hline
\end{tabular}

Notes: Germination, growth, and survival are the parameters measured (in the field and garden experiments) as indicated for seed, seedling, and adult targets. $\mathrm{A}=$ adult neighbor, $\mathrm{S}=$ seedling neighbor, 1 = year $1,2=$ year 2 . All estimates of competitive ability are mean relative interaction intensity values (RII), with the exception of the garden experiment, where survival shows the slope of the logistic, and mass is the fitted value for $c$ (see Methods). Increasing negative values indicate poorer competitive response, except for $c$, where increasingly positive values indicate poorer competitive response.

** $P<0.01 ; * * * P<0.001$.

$\dagger P<0.01$.

most individual correlations between the different measures of competitive ability and abundance positive (Table 3), but the average of all of the correlations of competitive response abilities with abundance was significantly positive, based on the $95 \%$ confidence interval (CI) of the mean $r_{\mathrm{S}}$ value generated by resampling procedures $($ mean $=0.437$, bias CI $=0.19-0.69, n=$ 11 ; excluding $r_{\mathrm{S}}$ value determined from $\left.n=4\right)$. All subsets of correlations similarly had mean $r_{\mathrm{S}}$ values significantly greater than zero (mean, bias CI, and $n$ for each: germination $0.806,0.52-0.93,2$; survival 0.235 , $0.02-0.50,6$; mass $0.404,0.14-0.80,3$; values were backtransformed from Z-transformed means and CI), but by far the highest means with the highest confidence intervals were those for germination and mass. The individual $r_{\mathrm{S}}$ values emphasize that abundance is most positively correlated with competitive ability in terms of germination and seedling growth, and generally poorly correlated with competitive ability in terms of seedling survival and adult growth and survival (Table 3).

\section{DISCUSSION}

These findings reveal a complex shift of interaction dynamics as plants move from seedling to adult life stages. First, the presence and magnitude of competitive response of any species depended on the demographic parameter and life history stage measured; overall competitive responses to neighbors were not consistent among germination, survival, and growth, and between seedlings and adults. Second, the rankings of competitive ability among species were concordant overall. However, when grouped by demographic parameter, competitive rankings based on size were strongly consistent but rankings based on survival were not (Table 4). Third, rankings for germination and seedling growth were much more strongly correlated with abundance than rankings for seedling survival, adult growth, or survival (Table 3 ). Fourth, even when net competitive effects or differences among species in those effects were not strong, species still differed in other qualities such as overall germination and survivorship (Table 2). The variation in the magnitude of neighbor effects among response components emphasizes the importance of evaluating competitive interactions at both seedling and adult stages, with more than target growth as an estimate of individual fitness.

\section{Overall magnitude of competition}

The magnitude of competition experienced by these old-field species varied among life history stages. Averaging over all species, competition reduced seedling growth by $78 \%$ and $68 \%$ (field and garden experiments, respectively), and adult growth by $92 \%$. The lower percent reduction suggests that seedlings are better response competitors than adults in this community. This result may be explained in part by the recognition that plant interactions fit into a continuum from facilitation to competition. Although seedlings are often thought of as more susceptible to competition, they also more often experience positive effects of neighbors (Callaway and Walker 1997). The environment experienced by seedlings is often moderated by shading from neighbors, to the point where water conditions are improved for seedlings under the canopy of adults (Callaway 1995). In this experiment, it may be that the positive and negative effects of neighbors counteract each other so that no net interaction could be detected for seedling germination and survivorship. As seedling targets grow, however, targets become more similar in size to 
TABLE 3. Extended.

\begin{tabular}{|c|c|c|c|c|c|}
\hline \multicolumn{6}{|c|}{ Survival } \\
\hline \multicolumn{5}{|c|}{ Field } & \multirow{2}{*}{$\begin{array}{c}\text { Garden } \\
\text { Seedling }\end{array}$} \\
\hline \multicolumn{4}{|c|}{ Seedling } & Adult & \\
\hline A1 & $\mathrm{A} 2$ & $\mathrm{~S} 1$ & $\mathrm{~S} 2$ & A & $\mathrm{S}$ \\
\hline 0.00 & 0.30 & . & 0.00 & 0.50 & 0.01 \\
\hline-0.61 & -0.53 & 0.01 & -0.43 & -0.33 & 0.00 \\
\hline 0.33 & $\ldots$ & -1.00 & $\ldots$ & -0.20 & -0.09 \\
\hline 0.00 & 0.00 & -1.00 & -1.00 & 0.50 & 0.03 \\
\hline 0.25 & 1.00 & 0.39 & 1.00 & 0.20 & \\
\hline$\ldots$ & $\ldots$ & $\ldots$ & $\ldots$ & $\ldots$ & -0.01 \\
\hline-0.33 & 0.00 & 0.00 & -0.75 & -0.60 & -0.67 \\
\hline 0.00 & -0.33 & 0.00 & -0.17 & -0.20 & -0.11 \\
\hline-0.04 & 0.14 & -0.09 & 0.09 & 0.35 & $0.68 \dagger$ \\
\hline
\end{tabular}

their neighbors, and the benefits of shading would be lost. Targets requiring high shade tolerance as seedlings would have more access to light towards maturity, but would also have increased water and nutrient requirements from higher transpiration and respiration costs. Competition for water and nutrients would also in-

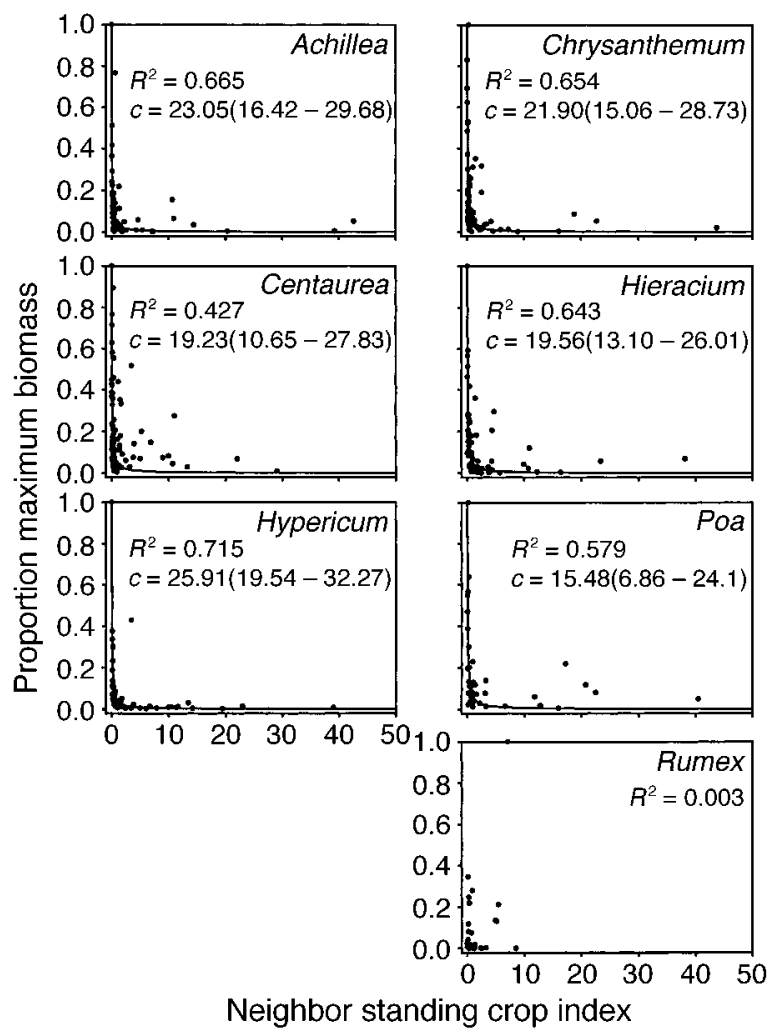

FIG. 3. Proportion of total target biomass as a function of an index of neighbor standing crop in the garden experiment. Nonlinear curve fits are shown, with the value for $c$ $( \pm 95 \% \mathrm{CI})$ and the $R^{2}$ for the fit. Due to the poor fit for Rumex, the curve and value for $c$ are not shown, and this species was excluded from the correlations of competitive ability with abundance. crease as the seedling roots grow into the rooting zones of neighbors. As a result, the balance of interactions may shift to being more competitive as individuals mature. Although facilitative interactions are becoming increasingly well documented (Callaway 1995, Callaway and Walker 1997), few studies have followed interactions from seedlings to adults to test if such shifts from facilitative to competitive effects over time are common.

The magnitude of competition experienced by these old-field species also varied drastically among demographic parameters. Seedling emergence and survival were largely unaffected by neighbors, and adult survival was only weakly affected by neighbors. Effects ranged from facilitation to competition, depending on species (Figs. 1 and 2). In contrast, both seedling and adult growth of almost all species were strongly inhibited by neighbors (Figs. 2 and 3). Thus, species appear to be much better response competitors for emergence and survival than for growth in this community. Many other studies of competition in old fields have quantified effects on germination (e.g., Goldberg 1987b, Reader 1993), seedling survival (e.g., Goldberg 1987b), seedling growth (Parrish and Bazzaz 1982, Miller and Werner 1987, Gurevitch et al. 1990, Wilson 1994, Gerry and Wilson 1995, Wilson and Tilman 1995, Collet et al. 1996) and adult survival (DiTommaso and Aarssen 1991) or growth (Goldberg 1987a, DiTommaso and Aarssen 1991). However, few have directly compared competition intensity among demographic parameters or life history stages, and none have compared both for the same set of species. Existing comparisons of competition intensity between survival and growth for both seedlings (e.g., De Steven 1991a, Berkowitz et al. 1995) and adults (DiTommaso and Aarssen 1991), as well as a meta-analysis among studies (Goldberg et al. 1999), show the same patterns as we find here; neighbors are less likely to negatively

TABLE 4. Concordance of rankings of competitive ability within grouped subsets of hierarchies. The tests are based on data from Table 3.

\begin{tabular}{lrcc}
\hline \hline \multicolumn{1}{c}{ Group } & $N$ & df & Kendall's $W$ \\
\hline All hierarchies & 11 & 3 & $0.485^{*} *$ \\
All seedlings & 7 & 3 & $0.459^{*}$ \\
All adults & 2 & 6 & 0.848 \\
Field experiment & 9 & 3 & $0.431^{*} *$ \\
Garden experiment & 2 & 5 & 0.800 \\
Germination & 2 & 6 & 0.701 \\
Size & 4 & 3 & $0.775^{*}$ \\
Size, seedlings only & 3 & 3 & $0.911^{*}$ \\
Survival & 6 & 3 & 0.075 \\
Survival, seedlings only & 5 & 3 & 0.028 \\
\hline
\end{tabular}

Notes: The number of hierarchies of competitive ability used in Friedman's ANOVA are indicated by $N$; df +1 were the number of species available for comparison among hierarchies. Kendall's $W$ indicates the level of correlation among hierarchies.

$* P<0.05 ; * * P<0.01$. 
influence survival, but tend to have strong negative effects on target growth. Thus, our result of stronger competitive effects on growth than on survival appears to be general, however, insufficient data are available yet to determine whether our findings of stronger effects on germination than survival or on adults relative to seedlings are also general.

\section{Hierarchies of competitive ability}

Adults differed strongly in their response competitive ability, both for survival and for growth. Such statistically detectable differences among species suggest strong hierarchies in competitive ability for these components of fitness. Apparently undetectable hierarchies for seed and seedling components of fitness suggest few differences in the response competitive ability of these components on species persistence in the community. Yet, the patterns among all hierarchies are remarkably different from what these tests suggest (Table 4). The most striking differences in concordance appear when hierarchies are grouped by demographic parameter. The rankings of competitive ability based on size are significantly concordant (Table 4). This pattern appears consistent among age classes; the sizebased hierarchies remain concordant when adult and seedling hierarchies for size are merged. For seed germination, hierarchies also appear consistent, but the pattern is not significant because of low sample size. Competitive rankings based on survival, however, are not consistent, indicating no relationship between rankings in survival. Thus, regardless of life stage, estimates of growth are likely to be related, but estimates of survival are not. These findings allow us to suggest the types and extent of measurements that should be made in future studies. As hierarchies of response of seedling growth are likely to reflect hierarchies of adult growth, one measure of growth or size would be sufficient. However, with the high variance in rankings based on survival, estimates of competitive hierarchies for both seedling and adult survival would be important in describing the competitive regime in a community.

\section{Competitive hierarchies and abundance}

Studies that measure hierarchies at both the seedling and adult life stages remain scarce. Thus, previous attempts to relate hierarchies of competitive ability to hierarchies of relative abundance within communities have generally used a single type of experimentallydetermined competitive hierarchy (Rabinowitz et al. 1984, Mitchley and Grubb 1986, Miller and Werner 1987, Wilson and Shay 1990, Shipley et al. 1991, Wilson and Tilman 1991). These have tended to show positive relationships, but most have used only hierarchies of seedling growth. We have suggested above that competitive ability based on seedling growth may be a good predictor of the same for adult growth, but that estimates based on seedling survival may not predict those based on adult survival. Given such variation among life stages, it is important to assess how competitive abilities at other stages are related to abundances; this may allow an indirect assessment of how each stage contributes to population growth and persistence in the community. In this study, we found that competitive abilities for seedling germination and seedling size were most strongly positively related to relative abundances. The most abundant species, Poa compressa, was reduced the least in germination and growth in the presence of adult neighbors, and was therefore the best competitor at these stages, while the least abundant species, Achillea millefolium, was reduced the most. This result is consistent with the common notion that early seedling establishment is crucial for population dynamics (Grubb 1977). However, it is surprising, given the overall results that competitive effects on germination were not significant and that species did not differ significantly in their competitive responses for germination (Table 2). One way to reconcile these seemingly contradictory results is to take into account year-to-year variation in the magnitude of competition. The results would be internally consistent if population dynamics are controlled by occasional years of strong competitive effects on seedling germination and competitive hierarchies are similar whether the magnitude is weak (as in this experiment) or strong. While it would be very difficult to test this hypothesis directly, it is consistent with the observation of strong competitive effects on seedling emergence in other studies of old-field herbs (Werner 1977), and strong variation in the magnitude of competitive effects among years in general (Parker and Muller 1982).

More generally, these two findings together indicate a partial decoupling between the proximate and ultimate effects of competition (sensu Welden and Slauson 1986) or the individual and community-level effects of competition (sensu Goldberg 1994). At short time scales, interspecific interactions are most pronounced for measures of seedling and adult growth, but competitive ability for adult growth appears to influence final abundance in the community less than competitive ability for seedling growth and competitive ability for germination. Further, the link between competitive ability for survival and abundance is poor, suggesting little influence of these proximate effects on the outcome of competition. Thus, our results emphasize the importance of studying multiple stages in studies of competition, as well as taking multiple approaches to studying the role of competition in communities. Simply quantifying the magnitude of competition for one or two components of fitness may not reveal the components of competition most influencing community structure.

\section{ACKNOWLEDGMENTS}

We thank R. Burnham, B. Rathcke, E. Werner, D. Zak, L. Hyatt, S. Wilson, B. Shipley, and an anonymous reviewer for critical readings of previous versions of this paper. Many people helped with field work, including S. Howard, R. Simp- 
son, A. Kaufmann, J. Kasmer, R. Thacker, R. Sherman, E. Jules, G. Nickerson, J. Courteau, K. Nash-Suding, C. Hershock, K. Glennemeier, A. Yarger, and H. Schubert. We thank them for their unselfish time and efforts. This research was supported by the Edwin S. George Reserve Fellowship, the University of Michigan Department of Biology Block Grant Program, the University of Michigan Rackham School of Graduate Studies One-Term Dissertation Fellowship, and The Nature Conservancy Small Grants Program.

\section{Literature Cited}

Antonovics, J., and N. L. Fowler. 1985. Analysis of frequency and density effects on growth in mixtures of Salvia splendens and Linum grandiflorum using hexagonal fan designs. Journal of Ecology 73:219-234.

Aplet, G. H., and R. D. Laven. 1993. Relative performance of four Hawaiian shrubby plants (Asteraceae) under greenhouse conditions with implications for rarity. Biological Conservation 65:15-21.

Austin, M. P., L. F. M. Fresco, A. O. Nicholls, R. H. Groves, and P. E. Kaye. 1988. Competition and relative yield: estimation and interpretation at different densities and under various nutrient concentrations using Silybum marianum and Cirsium vulgare. Journal of Ecology 76:157-171.

Berkowitz, A. R., C. D. Canham, and V. R. Kelly. 1995. Competition vs. facilitation of tree seedling growth and survival in early successional communities. Ecology 76 $1156-1168$.

Callaway, R. 1995. Positive interactions among plants. Botanical Review 61:306-349.

Callaway, R. M., and L. R. Walker. 1997. Competition and facilitation: a synthetic approach to interactions in plant communities. Ecology: 78:1958-1965.

Canham, C. D. 1988. Growth and canopy architecture of shade-tolerant trees: response to canopy gaps. Ecology 69 786-795.

Collet, C., J. M. Guehl, H. Frochot, and A. Ferhi. 1996. Effect of two forest grasses differing in their growth dynamics on the water relations and the growth of Quercus petraea seedlings. Canadian Journal of Botany 74:1562-1571.

De Steven, D. 1991a. Experiments on mechanisms of tree establishment in old-field succession: seedling emergence. Ecology 72:1066-1075.

De Steven, D. 1991b. Experiments on mechanisms of tree establishment in old-field succession: seedling survival and growth. Ecology 72:1076-1088.

DiTommaso, A., and L. W. Aarssen. 1991. Effect of nutrient level on competition intensity in the field for three coexisting grass species. Journal of Vegetation Science 2:513522

Gerry, A. K., and S. D. Wilson. 1995. The influence of initial size on the competitive responses of six plant species. Ecology 76:272-279.

Gleason, H. A., and A. Cronquist, 1991. Manual of vascular plants of northeastern United States and adjacent Canada. Second edition. The New York Botanical Garden, New York, New York, USA

Goldberg, D. E. 1987a. Neighborhood competition in an oldfield plant community. Ecology 68:1211-1223.

Goldberg, D. E. 1987b. Seedling colonization of experimental gaps in two old-field communities. Bulletin of the Torrey Botanical Club 114:139-148.

Goldberg, D. E. 1994. Influence of competition at the community level: an experimental version of the null models approach. Ecology 75:1503-1506.

Goldberg, D. E., T. Rajaniemi, J. Gurevitch, and A. StewartOaten. 1999. Matching questions and metrics of interaction strength in community ecology. Ecology 80:1118-1131.

Goldberg, D. E., and S. M. Scheiner. 1993. ANOVA and ANCOVA: field competition experiments. Pages 69-93 in S. Scheiner, and J. Gurevitch, editors. Design and analysis of ecological experiments. Chapman and Hall, New York, New York, USA.

Goldberg, D. E., and P. A. Werner. 1983. Equivalence of competitors in plant communities: a null hypothesis and a field approach. American Journal of Botany 70:1098-1104.

Grace, J. B. 1985. Juvenile vs. adult competitive abilities in plants: size-dependence in cattails (Typha). Ecology 66: $1630-1638$.

Grace, J. B. 1995. On the measurement of plant competition intensity. Ecology 76:305-308.

Grime, J. P. 1977. Evidence for the existence of three primary strategies in plants and its relevance to ecological theory. The American Naturalist 111:1169-1194.

Grubb, P. J. 1977. The maintenance of species-richness in plant communities: the importance of the regeneration niche. The Biological Review 52:107-145.

Grubb, P. J., D. Kelly, and J. Mitchley. 1982. The control of relative abundance in communities of herbaceous plants. Pages 79-97 in E. I. Newman, editor. The plant community as a working mechanism, special publications series of the British Ecological Society. Volume 1. Blackwell Science, Oxford, UK.

Gurevitch, J. 1986. Competition and the local distribution of the grass Stipa neomexicana. Ecology 67:46-57.

Gurevitch, J., P. Wilson, J. L. Stone, P. Teese, and R. J. Stoutenburg. 1990. Competition among old-field perennials at different levels of soil fertility and available space. Journal of Ecology 78:727-744.

Howard, T. G. 1998. The relationship of competitive hierarchies for germination, growth, and survivorship to relative abundance in an old field community. Dissertation. University of Michigan, Ann Arbor, Michigan, USA.

Howard, T. G. 2001. The relationship of total and per-gram rankings in competitive effect to the natural abundance of herbaceous perennials. Journal of Ecology 89(1), in press.

Keddy, P. A. 1990. Competition hierarchies and centrifugal organization in plant communities. Pages 265-290 in J. B. Grace and D. Tilman, editors. Perspectives on plant competition. Academic Press, London, UK.

Keddy, P. A., L. Twolan-Strutt, and I. C. Wisheu. 1994. Competitive effect and response rankings in 20 wetland plants: Are they consistent across three environments? Journal of Ecology 82:635-643.

Kunin, W. E. 1993. Sex and the single mustard: population density and pollinator behavior effects on seed-set. Ecology 74:2145-2160.

Markham, J. H., and C. P. Chanway. 1996. Measuring plant neighbor effects. Functional Ecology 10:548-549.

Miller, T. E., and P. A. Werner. 1987. Competitive effects and responses between plant species in a first-year old-field community. Ecology 68:1201-1210.

Mitchley, J., and P. J. Grubb. 1986. Control of relative abundance of perennials in chalk grassland in southern England I. Constancy of rank order and results of pot- and fieldexperiments on the role of interference. Journal of Ecology 74:1139-1166.

Parker, V. T., and C. H. Muller. 1982. Vegetational and environmental changes beneath isolated live oak trees (Quercus agrifolia) in a California annual grassland. American Midland Naturalist 107:69-81.

Parrish, J. A. D., and F. A. Bazzaz. 1982. Competitive interactions in plant communities of different successional ages. Ecology 62:314-320.

Rabinowitz, D., J. K. Rapp, and P. M. Dixon. 1984. Competitive abilities of sparse grass species: means of persistence or cause of abundance. Ecology 65:1144-1154.

Reader, R. J. 1993. Control of seedling emergence by ground cover and seed predation in relation to seed size for some old-field species. Journal of Ecology 81:169-175.

Rosenberg, M. S., D. C. Adams, and J. Gurevitch. 1999. 
MetaWin Version 2.00. Sinaur Associates, Sunderland, Massachusetts, USA.

SAS Institute. 1995. JMP statistics and graphics guide. Version 3.1. SAS Institute, Cary, North Carolina, USA.

Shipley, B., P. A. Keddy, and L. P. Lefkovitch. 1991. Mechanisms producing plant zonation along a water depth gradient: a comparison with the exposure gradient. Canadian Journal of Botany 69:1420-1424.

Silander, J. A., and S. W. Pacala. 1985. Neighborhood predictors of plant performance. Oecologia 66:256-263.

Suding, K. N., and D. E. Goldberg. 1999. Variation in the Effects of Vegetation and Litter on Recruitment Across Productivity Gradients. Journal of Ecology 87:436-449.

Tilman, D. 1982. Resource Competition and Community Structure. Princeton University Press, Princeton, New Jersey, USA.

Tilman, D. 1990. Mechanisms of plant competition for nutrients: the elements of a predictive theory of competition. Pages 117-141 in J. B. Grace and D. Tilman, editors. Perspectives on plant competition. Academic Press, London, UK.

Warner, R. R., and P. L. Chesson. 1985. Coexistence mediated by recruitment fluctuations: a field guide to the storage effect. The American Naturalist 125:769-787.
Watkinson, A. R. 1980. Density-dependence in single-species populations of plants. Journal of Theoretical Biology 83: 345-357.

Weiner, J. 1982. A neighborhood model of annual-plant interference. Ecology 63:1237-1241.

Welden, C. W., and W. L. Slauson. 1986. The intensity of competition versus its importance-an overlooked distinction and some implications. Quarterly Review of Biology 61:23-44.

Werner, P. A. 1977. Colonizing success of a 'biennial' plant species: experimental field studies of species cohabitation and replacement. Ecology 58:840-849.

Wilson, S. D. 1994. Initial size and the competitive responses of two grasses at two levels of soil nitrogen: A field experiment. Canadian Journal of Botany 72:1349-1354.

Wilson, S. D., and J. M. Shay. 1990. Competition, fire, and nutrients in a mixed-grass prairie. Ecology 71:1959-1967.

Wilson, S. D., and D. Tilman. 1991. Components of plant competition along an experimental gradient of nitrogen availability. Ecology 72:1050-1065.

Wilson, S. D., and D. Tilman. 1995. Competitive responses of eight old-field plant species in four environments. Ecology 76:1169-1180. 